\title{
DIRECT OVARIAN OBSERVATION IN THE PIG BY MEANS OF LAPAROSCOPY
}

\author{
D. E. WILDT, S. FUJIMOTO, J. L. SPENGER AND W. R. DUKELOW \\ Endocrine Research Unit, Michigan State University, East Lansing, \\ MI. 48823, U.S.A.
}

(Received 8th Fune 1973)

\begin{abstract}
Summary. The development of a laparoscopy technique in the gilt which allows repeated direct observation of ovarian cyclicity with minimal surgical stress and trauma is described. Follicular activity before, during and after ovulation can be observed as well as corpus luteum development, especially during critical periods, such as oestrus. This technique may have application in studies of early embryonic growth and as a tool for investigating the cause of early embryonic death.
\end{abstract}

To characterize ovarian morphology and activity in vivo, it has in the past been necessary to expose animals to major surgery, i.e. laparotomy. Due to the stress and trauma associated with this procedure, there has been a necessity for development of an improved technique.

Laparoscopy was first implemented as a means of direct observation and photographic documentation of the sequential ovarian processes in women (Semm, 1969). Studies in our laboratory have entailed adaptation of this technique for research on ovulation prediction and pregnancy diagnosis in a variety of species (Dukelow, Jarosz, Jewett \& Harrison, 1971; Harrison \& Dukelow, 1971; Jewett \& Dukelow, 1971, 1972; Rawson \& Dukelow, 1973).

The objective of our studies was to initiate and develop techniques of laparoscopy for observation studies on cyclic ovarian activity in the domestic pig.

Yorkshire gilts ranging from 7 to 9 months in age and 89 to $110 \mathrm{~kg}$ in body weight, were subjected to twice weekly laparoscopic examinations for up to 6 weeks. All animals were allowed free access to feed both before and after operation. The gilts were anaesthetized with sodium pentobarbitone (Halatal Solution, Jen-Sal Laboratories) at a level of 18 to $22 \mathrm{mg} / \mathrm{kg}$ body weight. The anaesthetic was injected into the jugular vein over a 15 - to 20-min period. In some cases, $1 \mathrm{mg}$ Promazine-HCl (Sparine, Wyeth Laboratories)/kg body weight was given intra-muscularly as a premedication to tranquillize the gilt before the injection of pentobarbitone.

The gilt was placed head down and supine on a $30^{\circ}$ sloped table modified from that described by Hulet \& Foote (1968) and Jarosz, Deans \& Dukelow (1971). The most satisfactory results were achieved when the hind legs were bound loosely with most of the body weight supported by a strap encompassing the animal's neck and bound to the anterior portion of the table (Pl. 1, Fig. 1). 
The laparoscope apparatus consisted of a $135^{\circ}$ paediatric laparoscope $5 \mathrm{~mm}$ in diameter, a fibre optic cable and a Model 4000 projector light source (Richard Wolf, Co., Knittlingen, West Germany). After surgical preparation, a trocar-cannula was inserted through a $1-\mathrm{cm}$ ventral mid-line incision just anterior to the position of the ovaries (Pl. 1, Figs. 2 and 3). The trocar-cannula was passed, subdermally, about $2 \mathrm{~cm}$ before entering the abdominal wall. This procedure allowed natural closure of the incision after examination and precluded the necessity for suturing. The trocar was then withdrawn and the laparoscope inserted (Pl. 1, Figs. 6, 7 and 8).

A tactile probe for manipulation of the internal organs was inserted at a point $10 \mathrm{~cm}$ lateral to the mid-line incision (Pl. 1, Fig. 5). To facilitate observation, the abdominal cavity was insufflated with $5 \% \mathrm{CO}_{2}$ in air through the gas attachment device of the cannula (Pl. 1, Fig. 4) (in other species, the gas is often administered by a verres cannula and this technique can also be used with swine).

Laparoscopic visualization of the ovaries was a relatively simple procedure and in a third of the observations, it did not require manipulation of the reproductive tract. Minor manipulation of the oviduct with the probe allowed complete ovarian examination in all cases. The ovary was usually located near the dorsolateral abdominal wall enclosed by the mesovarium. Slight manipulation with the probe allowed this mesentery to be moved for unobstructed observation of the ovary. Use of a graduated probe permitted measurement of the ovaries, follicles and corpora lutea. Morphological observations were documented with colour photographs taken with a Canon TL camera attached to the telescope for laparoscopy by means of a $95 \mathrm{~mm}$ adapter (Pl. 2, Figs 1 to 5). Kodak High Speed Ektachrome EHB film was used. Visualization and photographic techniques were facilitated by conducting laparoscopy in a darkened room.

The entire laparoscopy procedure, including anaesthetization, required 30 to $45 \mathrm{~min}$. Suturing the incisions was not necessary, but Nitrofurazone ointment or powder (Furacin, Eaton Laboratories) was applied as an antibacterial agent. Penicillin-streptomycin preparation $(600,000$ units penicillin, $750 \mathrm{mg}$ streptomycin) was administered following each laparoscopic procedure and no complications or infections were observed. Gilts recovered sufficiently in 2 to $3 \mathrm{hr}$ to be able to walk from the recovery room to pen quarters.

No adverse effects were observed resulting from twice-weekly sodium

\section{EXPLANATION OF PLATE 1}

Fig. 1. Gilt on sloped table. It can be observed that most of the weight of the animal is supported by the neck-strap and not by the rear leg bindings.

FIG. 2. Trocar-cannula being inserted into a $1-\mathrm{cm}$ mid-line incision.

FIG. 3. The gas supply hose attached to the cannula providing for abdominal insufflation.

Fig. 4. The inserted tactile probe used for manipulation of internal organs.

Fig. 5. The laparoscope apparatus being inserted through the abdominal cannula. The fibre optic cable can be observed leading to the anterior end of the laparoscope.

Fig. 6. Observation through the laparoscope. 
PLATE 1
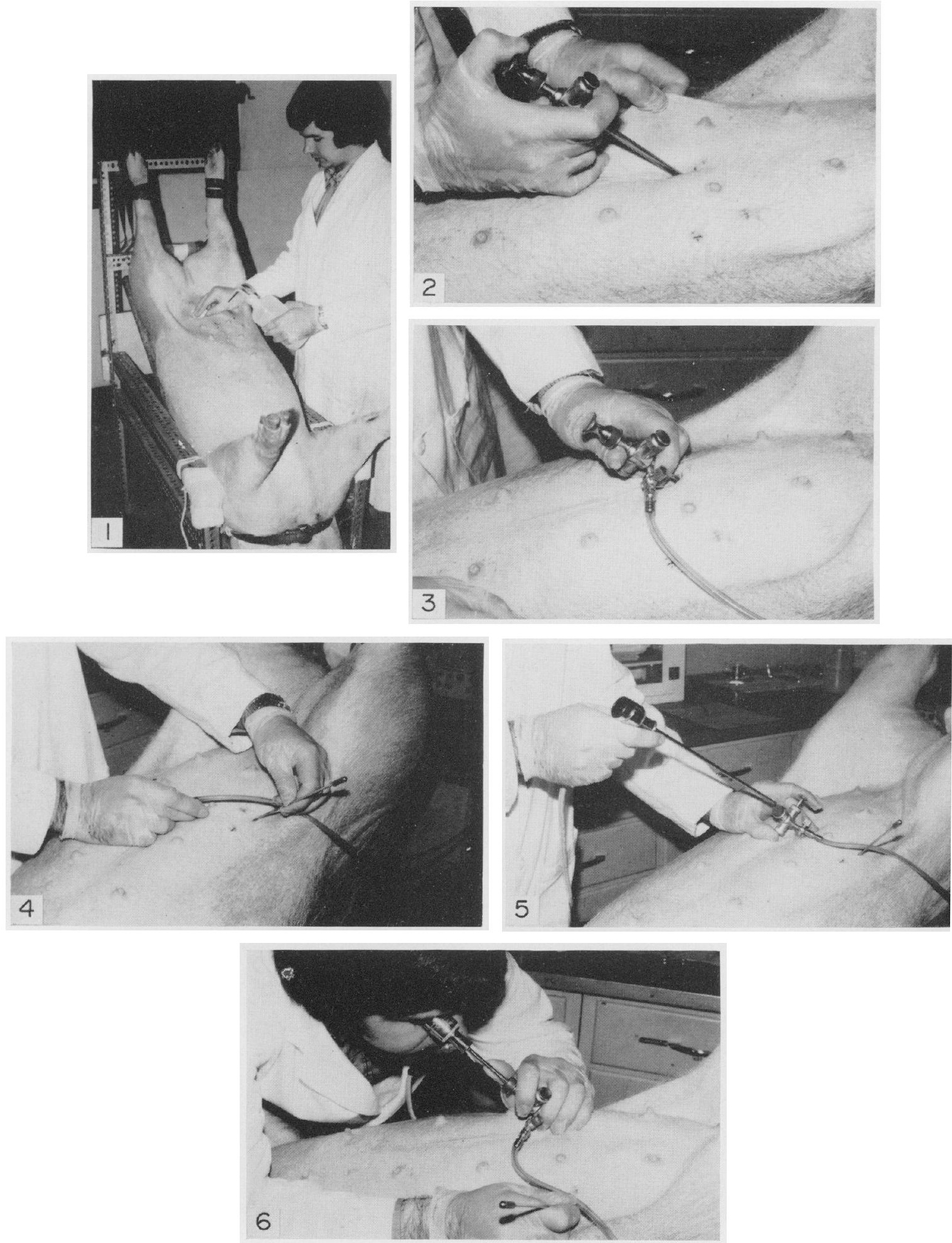

(Facing p. 542) 

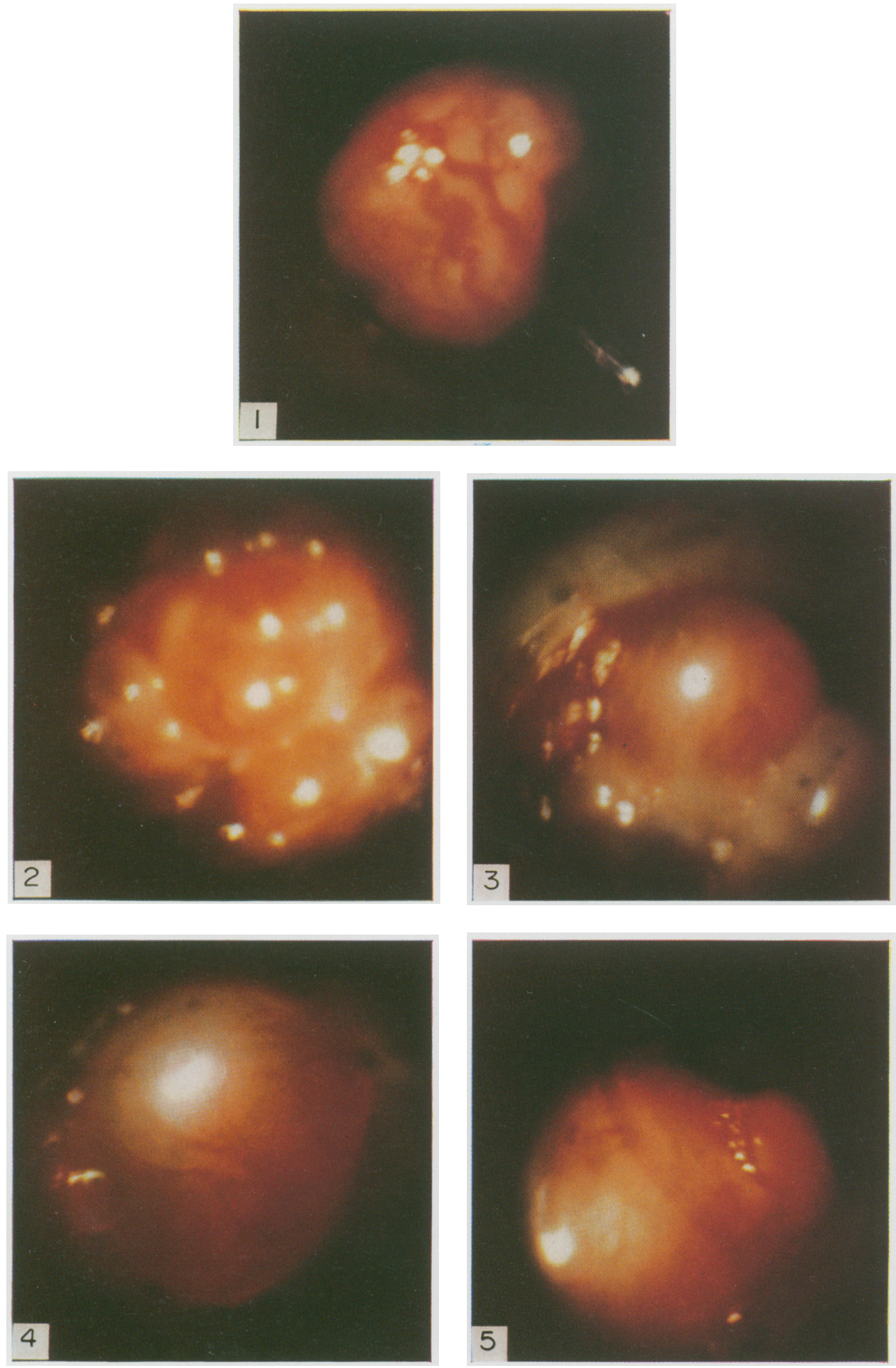

1., in: $1 \%, \quad, 13$

Downloaded from Bioscientifica.com at 04/26/2023 05:24:54AM via free access 
pentobarbitone administrations. Frequent use of this drug does necessitate attentive observation of dose requirements for effective anaesthesia.

The authors wish to express their gratitude to $\mathrm{Mr} \mathrm{J}$. M. R. Rawson for his advice and aid with photographic techniques. Appreciation is also expressed to Dr Elwyn Miller, Mr H. Dee Woody and Mr Roger Hale for their assistance with various phases of the project.

This research was supported by NIH contract 70-2061, USPHS grant 5-PO6-RR 00366-04 and NIH Research Career Development Award 1-K4HD35, 306-01. Michigan Agricultural Experiment Station Journal Article number 6848 .

\section{REFERENCES}

Dukelow, W. R., Jarosz, S. J., Jewert, D. A. \& Harrison, R. M. (1971) Laparoscopic examination of the ovaries in goats and primates. Lab. Anim. Sci. 21, 594.

HarRison, R. M. \& Dukglow, W. R. (1971) Megestrol acetate: its effect on the inhibition of ovulation in squirrel monkeys, Saimiri sciureus. 7. Reprod. Fert. 25, 99.

Hulet, G. V. \& Foote, W. G. (1968) A rapid technique for observing the reproductive tract of living ewes. F. Anim. Sci. 27, 142.

Jarosz, S. J., Deans, R.J. \& Dukelow, W. R. (1971) The reproductive cycle of the African pygmy and Toggenburg goat. F. Reprod. Fert. 24, 119.

JEWETT, D. A. \& DUkeLow, W. R. (1971) Follicular morphology in Macaca fascicularis. Folia primat. 16, 216.

JEWETT, D. A. \& DukeLow, W. R. (1972) Serial observations of follicular morphology near ovulation in Macaca fascicularis. J. Reprod. Fert. 31, 287.

Rawson, J. M. R. \& Dukelow, W. R. (1973) Observation of ovulation in Macaca fascicularis. F. Reprod. Fert. 34, 187.

Semm, K. (1969) Gynaecological pelviscopy and its instrumentation. Acta fertil. europ. 1, 81.

\section{EXPLANATION OF PLATE 2}

Ovarian observations of a gilt achieving her first pubertal oestrus

Fig. 1. Ovary of a prepubertal gilt with mesovarium intact, 21 days before the gilt first demonstrated oestrus.

Fig. 2. Same ovary as in Fig. 1 with mesovarium removed, 13 days before first demonstrated oestrus. Extensive follicular development and absence of luteal tissue can be observed. Fig. 3. Preovulatory follicle on first day of oestrus. The removed fimbria is visible in the background.

Fig. 4. Ovulatory follicle taken $36 \mathrm{hr}$ after the beginning of oestrus. Extensive vascularity can be observed across the surface of the follicle.

Fig. 5. Corpus luteum flattened and haemorrhagic in appearance on Day 7 of the cycle (counting first day of oestrus as Day 1 ). 